\title{
Experimental study of blast loading behind a building corner
}

\author{
T. Gajewski ${ }^{1}$ (1) - P. W. Sielicki ${ }^{1}$ (]
}

Received: 7 February 2019 / Revised: 14 October 2019 / Accepted: 10 January 2020 / Published online: 30 January 2020

(c) The Author(s) 2020

\begin{abstract}
The paper presents unique blast experiments in reference to scientific literature and official standards. Experimental scenarios reflect a hypothetical realistic combat situation of a human being covered from a blast wave behind a rigid building corner. In the scenario assumed, the overpressure loads affect the lungs while the person is standing or the eardrums while the person is kneeling at the aiming position. The paper presents 27 free-field experiments measuring the overpressure loads. All the measurements were taken behind the right angle of the rigid wall. Two masses of TNT were considered: $200 \mathrm{~g}$ and $400 \mathrm{~g}$. In the selected cases, a low test-to-test variability of the measured data was observed. Detailed plots of overpressure versus time are presented for various distances behind the building corner and TNT charge masses. Peak overpressure versus positive impulse plots are also demonstrated. Furthermore, the safety thresholds regarding different locations behind the building corner are defined for the considered explosive masses.
\end{abstract}

Keywords Blast wave $\cdot$ Experiment $\cdot$ Human safety $\cdot$ Injury criteria $\cdot$ Building corner

\section{Introduction}

To conduct experimental parametric blast studies is important for understanding and explaining such complicated phenomena as explosions and their influence on the surrounding environment. For instance, parametric laboratory studies were conducted in [1], in which PE4 explosive was analysed. Although the explosive shapes, dimensions, and masses were varied, some experiments cannot be replaced by laboratory tests due to the blast scenario, see, for instance, [2], where the shock tube and field test comparison was discussed. The most important conclusion from [2] is that laboratory tests require a very careful experimental set-up and a deep insight into the experimental model in order to avoid wrong conclusions. There are also studies which describe reduced-scale experiments, for instance, [3] or [4]. It is not always possible to transfer the knowledge from reduced-scale tests to full-scale tests. The full-scale approach exceeds the reducedscale approach in terms of ignition charge volume, weather

Communicated by C. E. Needham.

T. Gajewski

tomasz.gajewski@put.poznan.pl

1 Institute of Structural Analysis, Poznan University of Technology, Poznan, Poland conditions, and acquisition equipment accuracy. However, as it was noted by Hao et al. [5], "the full-scale field blast test is usually expensive and complex", but there is no doubt that such study data are scientifically and practically valuable. In full-scale field tests, it is important to establish the testto-test variability as shown in $[6,7]$. The parametrization of physical magnitudes is useful to understand the physical relations involved, as was done in [6], which was a field study. In this research, the interaction between a blast wave and a sand hill was tested. The stand-off distance was parametrized, and distances of 0.6, 0.8, 1.0, 1.2, 1.4, and $1.6 \mathrm{~m}$ were set. The data obtained from such field studies of blasts may be used to improve people's safety.

Before designing personal protection systems, a credible prediction of the blast loading conditions is required. The use of explosives in armed conflicts, or due to criminal activities, has influenced the increased need for developing personal protective systems for soldiers and police officers directly involved in combat. Blast pressure in the case of a free-space explosion is relatively easy to predict; however, the pressure propagation in a real combat environment is a more complex phenomenon and, thus, difficult to estimate by the simplified approaches. The blast pressure depends on external influences, such as the urban geometry, ground stiffness, charge shape, and mass. In this experimental work, a typical urban combat environment was imitated in the field 
tests, i.e., a protected and unprotected human individual covered behind the building corner. The scenario was assumed in order to measure the level of blast pressure exerted on the personal protective gear or the human body itself in one of the most frequently occurring combat situations.

In the professional literature, there is no evidence of research studying the blast wave behaviour behind the building corner at a small stand-off distance and with relatively small explosive charges. The field tests presented in this paper were conducted in order to gain deeper insight into the blast wave behaviour and pressure levels behind the corner. Various masses of trinitrotoluene (TNT) charges were used, and measurements were taken at different positions behind the building corner.

Technical reports and official standards assume simplified conditions; thus, the accuracy of the estimation of the blast loads in complex situations is insufficient. For instance, according to UFC 30340-02 standard [8, 9], the peak pressure acting on the side wall is estimated as a uniform value of blast pressure for the roof and side walls. The mitigation effect due to the distance is well recognized; for instance, it was presented in [6], which is an experimental paper. Thus, while discussing safety of people behind the building corner, the mitigation effect should be taken into consideration. Moreover, in order to use the formula from this standard $[8,9]$, the distance to the building must be large enough to meet the assumptions. To sum up the study mentioned above, the pressures are measured in a situation mimicking a real one for which the UFC 30340-02 standard conditions are not applicable because the distance from the wall is too small, e.g., the scaled distance to the obstacle is smaller than $0.7 \mathrm{~m} / \mathrm{kg}^{1 / 3}[7,8]$. Moreover, according to the recent study of Codina and Ambrosini [10], UFC 30340-02 overestimates the impulse on the side walls.

The main advantage of this experimental study is that the results are available to the public. Such explosive experimental studies are usually carried out for government agencies, and thus, their distribution is limited.

\section{Materials and methods}

The dimensions of the experimental set-up result from a hypothetically real scenario. Figure 1a presents the schematic of the experimental set-up, while Fig. $1 \mathrm{~b}$ represents its real site view. In the schematic, the explosive is placed at a distance of $0.5 \mathrm{~m}$ from the front wall and $1.0 \mathrm{~m}$ from the side covering wall. The walls as well as the flat roof of the structure were made of 0.2 -m-thick reinforced concrete slabs. The structure in the schematic is $4.0 \mathrm{~m}$ long and $4.0 \mathrm{~m}$ wide and has a height of $2.7 \mathrm{~m}$. The blast pressures were measured $0.35 \mathrm{~m}$ from the side covering wall, since this is the average distance to the chest while a person is standing next to the wall perpendicular to the covering wall plane (Fig. 1). Four measurement positions were used: $A, B_{1}, B_{2}$, and $\mathrm{B}_{3}$. In each test, a measurement was taken at position $A$, while positions $B_{1}, B_{2}$, and $B_{3}$ were used alternately, one at a time. Position A was used to check the wavefront value arriving directly from the explosive, and positions $B_{1}$, $\mathrm{B}_{2}$, and $\mathrm{B}_{3}$ were measured to determine the blast pressure change along the covering wall. The distances between all positions marked $\mathrm{B}$ were $0.5 \mathrm{~m}$. The $\mathrm{B}_{0}$ position (Fig. 1a) was eliminated from considerations in order to exclude the data which would be difficult to interpret (due to vortex and complex reflection). The explosive was hung on thin strings in a horizontal position at a height of $1.35 \mathrm{~m}$ from the ground, which is half of the wall height. The pressures at positions $\mathrm{A}, \mathrm{B}_{1}, \mathrm{~B}_{2}$, and $\mathrm{B}_{3}$ were registered at the same height from the ground, i.e., $1.35 \mathrm{~m}$. The height of $1.35 \mathrm{~m}$ represents the height of the chest centre for a standing position or the height of the eardrums for the aiming-kneeling position, for a medium-sized person.
Fig. 1 Explosion scenario: a schematic, b real view
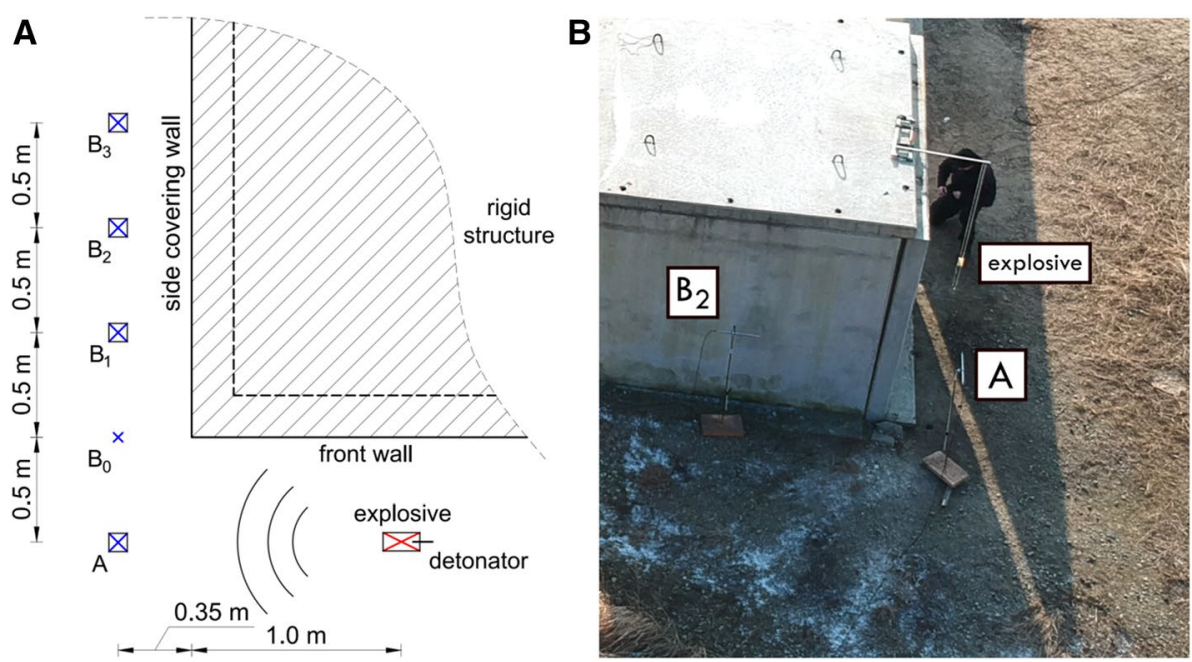
The explosive used in all field tests was trinitrotoluene (TNT). The explosive was selected due to its popularity in blast research. The material was used in many recent studies [11-13]. The indicative TNT equivalencies are widely available, e.g., in [5]. The explosive may be characterized by high repeatability, which is also well documented. The explosive charge was brick-shaped (200 g bricks of $5 \mathrm{~mm} \times 2.5 \mathrm{~mm} \times 10 \mathrm{~mm}$ ) and was positioned horizontally. There was a wired electric detonator connected from the back of the scene (Fig. 1a), and the ignition point was located at the centre of the charge. The longer horizontal edge of the charge was perpendicular to the front wall. Two masses of TNT charges were used during the field tests: $200 \mathrm{~g}$ and $400 \mathrm{~g}$.

The free-field experiments, especially with high-speed dynamics, require researchers' experience and know-how. In this test, one of the important factors responsible for accuracy is the weather. First, it was found during the tests that due to the wind gusts, the charge oscillated in the horizontal plane. The translational movements were less than $\pm 1.5 \mathrm{~cm}$, and the rotations were less than $\pm 5^{\circ}$. Second, it is accepted by the scientific community that the wave propagation through the ambient air depends on the weather conditions, especially on the ambient pressure and humidity. Those weather factors are present in many phenomenological formulae, for instance, the ones used in $[14,15]$. Unfortunately, many experimental and numerical studies omit that important information when reporting their results. The weather conditions during the free-field tests presented here are shown in Table 1. The tests were conducted in 2 days. The series on day 1 were carried out during the end of winter, whereas the series on day 2 were done during the end of summer, and therefore, the air temperature is different.

In Table 2, the summary of the detonation results is shown, while the full set-up information of the experimental tests is presented in the Appendix. Test-to-test variability is provided since each test set-up (the same TNT mass and $\mathrm{B}$ as the measurement position) was repeated three times, similar to $[4,16]$. Tests were conducted in 2 days. During the first day, there were nine detonations of a 200-g charge each time (three measured at $\mathrm{B}_{1}$, three at $\mathrm{B}_{2}$, and three at $B_{3}$ ). During the second day, there were nine detonations of a 200-g charge (measured as above at $\mathrm{B}_{1}, \mathrm{~B}_{2}$, and $\mathrm{B}_{3}$ ) and nine detonations of a $400-\mathrm{g}$ charge (measured as above at

Table 1 Weather conditions measured on the site during free-field tests

\begin{tabular}{lclll}
\hline & $\begin{array}{l}\text { Air tem- } \\
\text { perature } \\
\left({ }^{\circ} \mathrm{C}\right)\end{array}$ & Air pressure $(\mathrm{hPa})$ & Humidity $(\%)$ & $\begin{array}{l}\text { Wind } \\
\text { speed } \\
(\mathrm{m} / \mathrm{s})\end{array}$ \\
\hline Day 1 & 3.8 & 1010.0 & 47 & 0.0 \\
Day 2 & 20.0 & 1003.0 & 58 & 3.4 \\
\hline
\end{tabular}

$\mathrm{B}_{1}, \mathrm{~B}_{2}$, and $\mathrm{B}_{3}$ ). After each detonation, the blast pressures were measured at position $\mathrm{A}$ and at one of the $\mathrm{B}$ positions.

The magnitudes recorded at positions A and B during all tests were the blast pressure histories. The authors used two ICP ${ }^{\circledR}$ blast pressure pencil probes. The maximum pressure limit for these sensors is $345 \mathrm{kPa}$. Figure 1a shows the detailed location of the sensors. Both of them were located $1.35 \mathrm{~m}$ above the ground (Fig. 2b, d). The pencil probe at the A position was oriented towards the explosive, whereas the probe at $\mathrm{B}_{1}, \mathrm{~B}_{2}$, and $\mathrm{B}_{3}$ was perpendicular to the probe at $\mathrm{A}$. The time resolution for air pressure measurements is $0.02 \mathrm{~ms}$ for all gauges. A Vibdaq 2.1 acquisition apparatus was used for recording the gauge signal. In this case, a portable computer with a PCB signal conditioner was sufficient to record the signal correctly at a distance of $50 \mathrm{~m}$ from the explosion site. This was a safe location for the measurement team and hardware.

All field experiments were photographed and recorded at the site to document the testing. Selected photographs are shown in Fig. 2 in order to present the experimental study and technical set-up. In Fig. 2a, the general field view is presented with the side covering wall (left) and the front wall (right) visible, as well as the horizontally oriented TNT charge hung on the strings (magnified) and two pencil gauges (at positions $\mathrm{A}$ and $\mathrm{B}_{1}$ ). Figure $2 \mathrm{~b}$ shows the site from another point of view. In comparison with Fig. 2a, a ninety-degree view is shown, with only the side covering wall visible. During the measurements, the probes at the A and B locations were perpendicular to each other (Fig. 2c). In Fig. 2d, a bird's-eye view photograph taken from an unmanned aerial vehicle (a quadcopter drone) soon after the detonation to present the overall scenario is shown.

\section{Results and discussion}

In the experimental approach, the assumed scenario represents a combat situation of a human covered from the blast behind the building corner. This situation may involve special force members, soldiers, police officers, or civilians. It may refer to the moment just before the combat. They may stand or kneel when aiming or hiding. It also refers to the situation when a civilian runs away from danger and looks for cover. In both cases, people are exposed to the potentially harmful blast wave, being just behind the corner, i.e., at a distance of less than $1.5 \mathrm{~m}$.

The main objective of the study was to measure the blast pressures over the building corner. In Table 2, there is a list of detonation events with the corresponding impulses, maximal overpressures, and their times of arrival. Moreover, the source overpressure curves are presented in Figs. 3, 4, and 5. In Figs. 3 and 4, the results from 200-g charge detonations are presented. They took place on day 1 and day 
Table 2 Summary of the results of blast measurements conducted in the study

\begin{tabular}{|c|c|c|c|c|c|c|c|}
\hline No. & Case & $\begin{array}{l}\text { Arrival time } \\
\text { at } A(\mathrm{~ms})\end{array}$ & $\begin{array}{l}\text { Max. over- } \\
\text { press. at A } \\
(\mathrm{kPa})\end{array}$ & $\begin{array}{l}\text { Impulse at } \mathrm{A} \\
(\mathrm{kPa} \times \mathrm{ms})\end{array}$ & $\begin{array}{l}\text { Arrival } \\
\text { time at B } \\
(\mathrm{ms})\end{array}$ & $\begin{array}{l}\text { Max. over- } \\
\text { press. at B } \\
(\mathrm{kPa})\end{array}$ & $\begin{array}{l}\text { Impulse } \\
\text { at } \mathrm{B} \\
(\mathrm{kPa} \times \mathrm{ms})\end{array}$ \\
\hline 1. & $\mathrm{~B}_{1}-200 \mathrm{~g}$ & 1.92 & $109.5^{*}$ & 60.5 & 2.50 & 51.0 & 24.8 \\
\hline 2. & & 1.36 & $101.1^{*}$ & 66.3 & 2.61 & 50.1 & 25.9 \\
\hline 3. & & 1.33 & 90.5 & 72.9 & 2.68 & 50.5 & 25.1 \\
\hline 4. & $\mathrm{~B}_{2}-200 \mathrm{~g}$ & 1.54 & 146.0 & 59.3 & 3.46 & 21.9 & 17.8 \\
\hline 5. & & 1.32 & 99.6 & 68.6 & 3.94 & 30.4 & 18.6 \\
\hline 6. & & 1.36 & 131.2 & 74.2 & 4.32 & 25.7 & 18.2 \\
\hline 7. & $\mathrm{~B}_{3}-200 \mathrm{~g}$ & 1.52 & 137.1 & 64.5 & 5.00 & 20.0 & 15.2 \\
\hline 8. & & 1.32 & 84.1 & 61.0 & 5.39 & 17.1 & 14.7 \\
\hline 9. & & 1.34 & $86.2 *$ & 55.3 & 5.28 & 14.1 & 17.1 \\
\hline 10. & $\mathrm{~B}_{1}-200 \mathrm{~g}$ & 2.14 & $71.0 *$ & 53.5 & - & - & - \\
\hline 11. & & 1.33 & 161.6 & 52.6 & 1.81 & 26.5 & 24.8 \\
\hline 12. & & 1.35 & 126.9 & 59.4 & 2.29 & 34.4 & 25.8 \\
\hline 13. & $\mathrm{~B}_{1}-400 \mathrm{~g}$ & 1.16 & 220.6 & 82.9 & 1.94 & 90.2 & 41.1 \\
\hline 14. & & 1.13 & 134.0 & 58.3 & 1.92 & 74.1 & 35.8 \\
\hline 15. & & 1.17 & 174.0 & 68.6 & - & - & - \\
\hline 16. & $\mathrm{~B}_{2}-200 \mathrm{~g}$ & 1.67 & $108.5^{*}$ & 56.4 & 3.58 & 28.1 & 20.7 \\
\hline 17. & & 1.36 & $73.4 *$ & 55.2 & 3.63 & 28.6 & 18.5 \\
\hline 18. & & 1.91 & $79.8^{*}$ & 54.2 & 3.70 & 20.7 & 22.3 \\
\hline 19. & $\mathrm{~B}_{2}-400 \mathrm{~g}$ & 1.16 & 203.7 & 70.1 & 2.58 & 41.5 & 28.8 \\
\hline 20. & & 1.16 & 256.3 & 95.7 & 3.31 & 42.7 & 25.8 \\
\hline 21. & & 1.12 & 151.7 & 68.3 & 3.06 & 41.1 & 34.4 \\
\hline 22. & $\mathrm{~B}_{3}-200 \mathrm{~g}$ & 1.34 & 94.6 & 47.7 & 4.82 & 23.7 & 19.2 \\
\hline 23. & & 1.34 & 111.5 & 60.9 & - & - & - \\
\hline 24. & & 1.41 & 140.6 & 49.2 & 4.29 & 13.3 & 12.4 \\
\hline 25. & $\mathrm{~B}_{3}-400 \mathrm{~g}$ & 1.16 & 335.8 & 90.4 & 3.93 & 34.8 & 24.2 \\
\hline 26. & & 1.17 & 176.8 & 72.7 & 4.50 & 36.7 & 22.1 \\
\hline 27. & & - & - & - & - & - & - \\
\hline
\end{tabular}

*Two peaks appear in the positive phase
2, respectively. The data in Fig. 5 cover the results for 400-g charge detonations on day 2. In Figs. 3, 4, and 5, the left-hand side plots show the measurements at position A, whereas the right-hand side plots present the measurements from the positions marked as $\mathrm{B}$, as indicated by the plot header. In some of the cases for position A recordings, the overpressure was disturbed by the occurrence of the second positive peak. In Table 2 , these cases are marked by an asterisk (*). One of these cases is test no. 9 (Fig. 3, left plot). In this test, the primary overpressure peak was $86.2 \mathrm{kPa}$ with the arrival time of $1.34 \mathrm{~ms}$, whereas the second overpressure peak was $79.8 \mathrm{kPa}$ with the arrival time of $1.98 \mathrm{~ms}$.

As expected, the overpressures at position A are larger than the corresponding ones at the positions marked as B: the blast wave is measured closer to the detonation site; thus, less blast wave energy is dissipated. The time axes are synchronized to have 0.0 at the moment of detonation. The pressure peak at A is observed at about $1.27 \mathrm{~ms}$ for $200 \mathrm{~g}$ of TNT (Figs. 3, 4) and at $1.06 \mathrm{~ms}$ for $400 \mathrm{~g}$ of TNT (Fig. 5). At the positions marked as B, the arrival times shift with increasing distance behind the building corner $(0.5,1.0$, and $1.5 \mathrm{~m})$. The peak value decreases further away from the corner.

A summary of the plots in Figs. 3, 4, and 5 is presented in Fig. 6 . The average overpressure peaks from measurements at the positions marked as B were calculated for 200-g (circles) and 400-g (squares) TNT charges and referred to the distance behind the corner. This shows how the overpressure peaks decrease with increasing distance behind the corner. In the plot, the minimal and maximal peaks are also shown (the upper and lower horizontal bars, respectively). The data presented in the figure were interpolated by cubic functions. According to the data, the conclusion can be drawn that the measurements show low test-to-test variability in the selected cases. For instance, in Fig. 3 (B1 case), the impulses (thin lines) differ less than 5\% at the end of the positive phase $(3.9 \mathrm{~ms})$. A similar agreement was obtained for the B2 and B3 impulses in Fig. 3. The peak values in Fig. 5 (B2 case) may be another example of low test-to-test variability, 
Fig. 2 Field tests documented in photographs: the whole scene (a), the scene behind the corner (b), perpendicular pressure gauges (c), the bird's-eye view during the explosion $(\mathbf{d})$
A

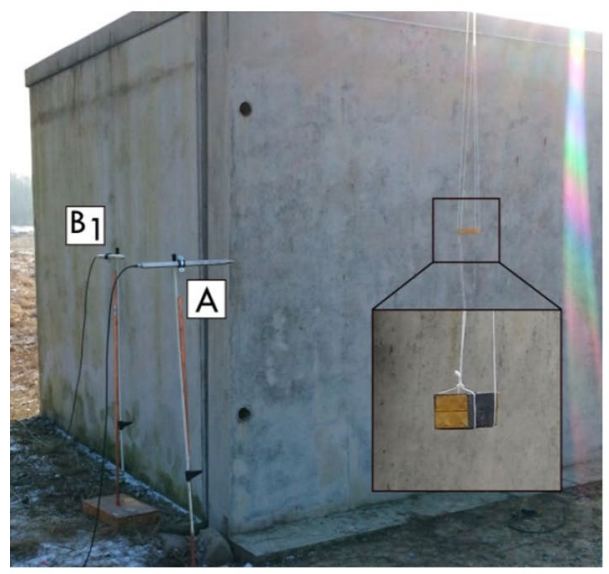

C

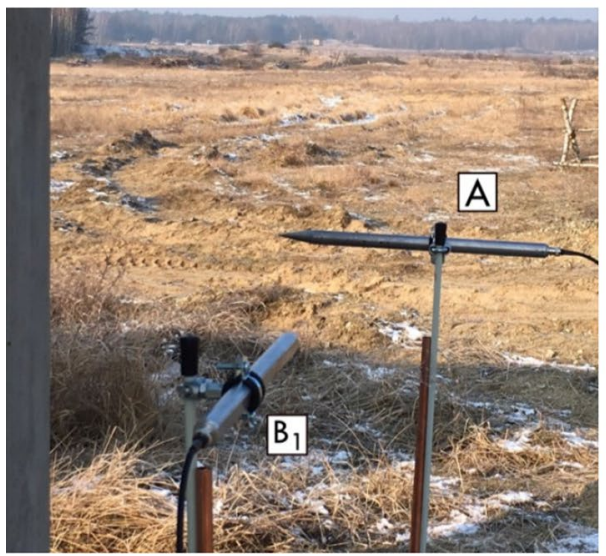

B

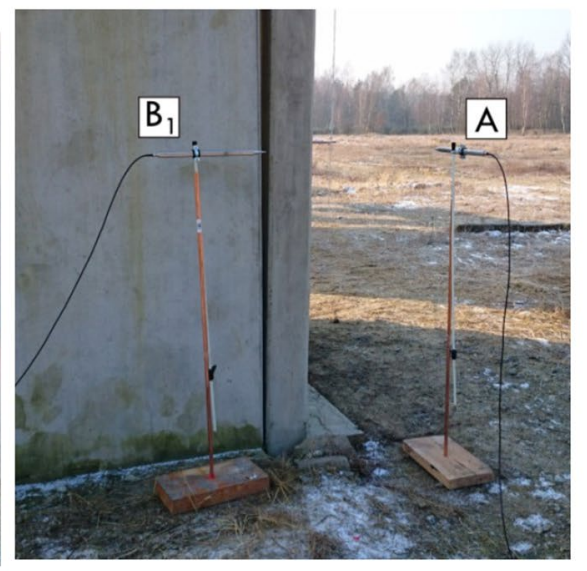

D

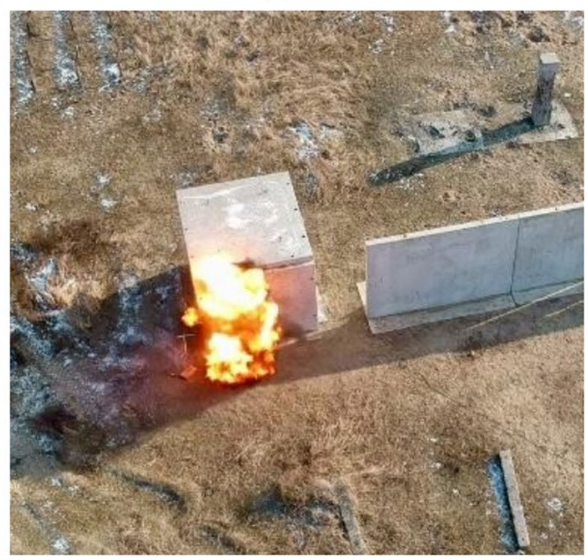

where the mean value from three trials (Table 2, trials 19, 20 , and 21) is $41.8 \mathrm{kPa}$ with a standard deviation of $0.7 \mathrm{kPa}$.

A preliminary assessment of the blast overpressure in air is possible using simplified empirical formulas. However, subsequent reflections of the blast wave from a different medium, other than air, cause an important pressure change. Moreover, if the surrounding geometry is complex, e.g., an irregular city geometry or the corridors inside a building, it is very hard to predict the loading conditions precisely by the equations. For that reason, only reproducible actual experiments give the real outcomes.

In the present study, position A was considered only in order to verify whether or not the measurements are correct. This was proved by comparing the magnitudes of pressure with values from the simplified formulas from $[9,17,18]$. The closest pressure gauge (position A in Fig. 1) was located at a distance of $1.35 \mathrm{~m}$ from the explosive. According to these formulas, for a free-air explosion, the scaled distance values are 2.31 and $1.83 \mathrm{~m} \times \mathrm{kg}^{-1 / 3}$ for the 200- and 400-g charges at position A. The loading conditions can be obtained based on the empirical formulas and using the above scaled distances, resulting in the free-field overpressures equal to $142 / 237 \mathrm{kPa}$ with the associated positive impulses $47 / 74 \mathrm{kPa} \times \mathrm{ms}$ for both charges, respectively (Table 3). In the paper, the average outcomes for the freefield overpressures and positive impulses are 109/206 $\mathrm{kPa}$ and $60 / 76 \mathrm{kPa} \times \mathrm{ms}$ for the two cases with 200 - and 400-g charges (Figs. 3 and 4, position A). The maximal difference between the values obtained from the simplified formulas and experiments is $30 \%$.

Another interesting observation found during the series of experiments carried out in the present study is related to the blast wave interaction with the corner of the structure and subsequently reached points, such as the front wall, the ground, the corner, the gauges, and the ground behind the corner. According to the authors' results, for the given geometry and 200-g scenario the blast wave reaches the front wall $0.23 \mathrm{~ms}$ after the explosion. Next, about $1 \mathrm{~ms}$ later, the ground area below the explosive and the first pressure gauge (A) are covered. The same wave then goes to the perpendicular wall surface and subsequently through the points marked B1, B2, and B3. At the same time, the first wave is reflected from the ground, below the TNT charge, goes to the front wall and pursues the first wave, which is now behind 
Fig. 3 Pressure histories for 200-g TNT charges and different positions, day 1
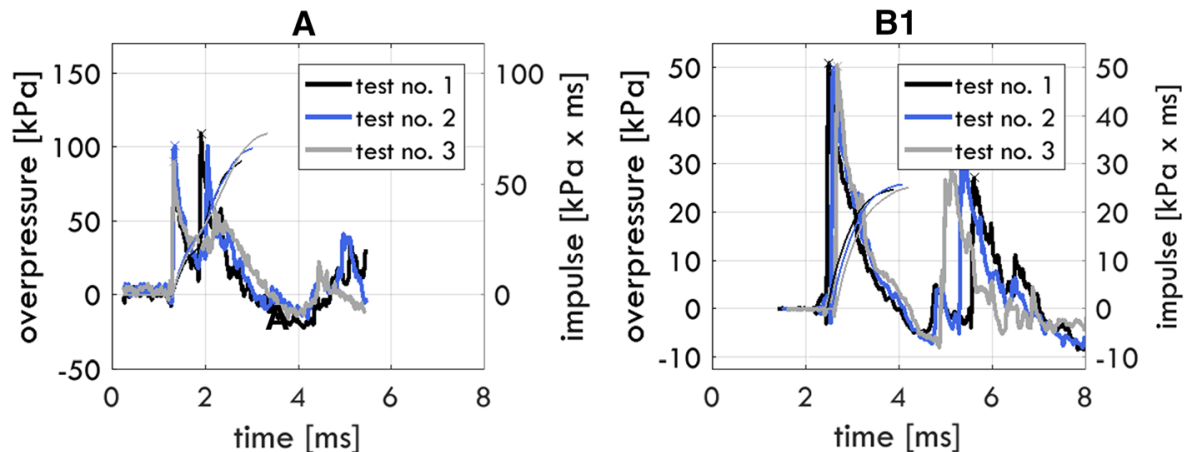

A

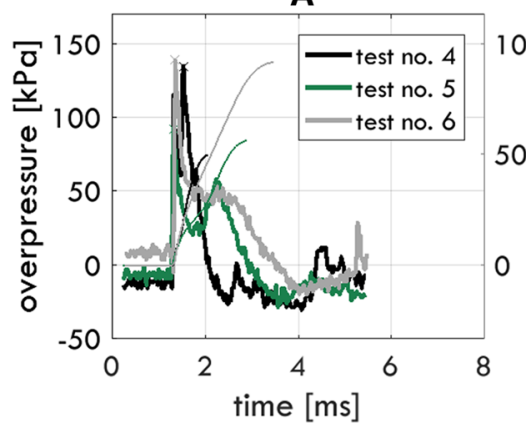

A

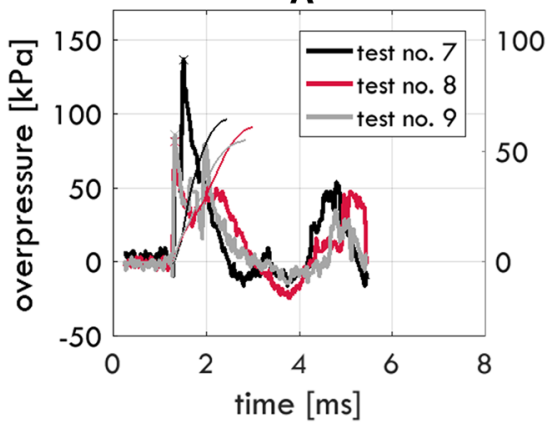

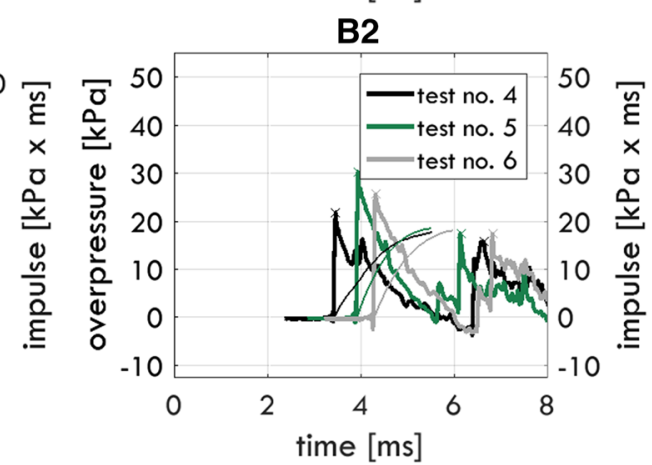

B3

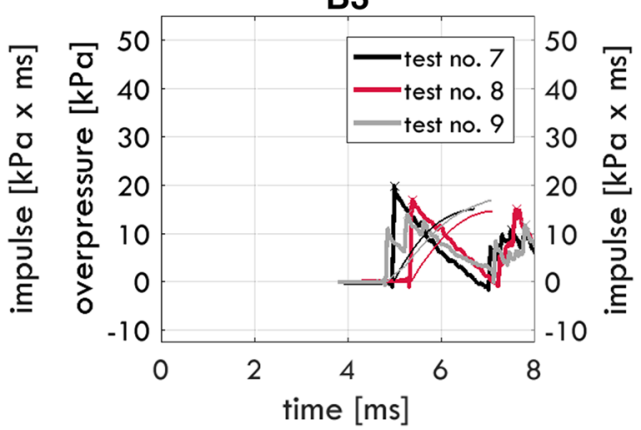

the corner. Moreover, the ground and wall reflected waves reach the point A $4.5 \mathrm{~ms}$ after the detonation. Finally, after 5-7 ms, the second wave goes through points marked as B.

The results obtained in the study are compared with the criteria for human safety under an explosive loading. For this purpose, based on Fig. 6, the overpressure versus impulse (PI) plot is presented in Fig. 7 (red circles for 200-g charges and blue squares for 400 -g charges). The safety criteria refer to different aspects. The best known thresholds from [9] deal with lungs and eardrums. Another example of these criteria may refer to the brain acceleration, e.g., Wayne State Tolerance Curve [19] or the cervical spine, as used in [20]. In Fig. 7, the criteria for lungs and eardrums are presented and they are marked with dash-dotted and dashed lines, respectively. All those criteria refer to the incident pressure. In reference to the standard levels of human safety for eardrums and lungs, the PI plots obtained in the study are shown as an outcome of 27 explosive tests.
Two safety thresholds for the lung damage from [9, 21] are presented in Fig. 7, dash-dotted lines. The criteria apply to a standing person with the chest centre at $1.35 \mathrm{~m}$ from the ground. The person's weight of $70.8 \mathrm{~kg}$ is considered, since this is an average human body mass of European population [22]. The first threshold based on the Unified Facilities Criteria (UFC) is constant up to approximately $120 \mathrm{kPa} \times \mathrm{ms}$. After $120 \mathrm{kPa} \times \mathrm{ms}$, it decreases rapidly. The second threshold, from Ono et al. [21], is lower. It decreases almost linearly in the domain of the experimental values. These two criteria are higher than the experimental values. Thus, it seems that the person would be safe in the present detonation scenario as far as the lung damage is concerned (see the distances and TNT masses). It is worth emphasizing that position $B_{1}$ with the $400-\mathrm{g}$ charge is the most dangerous one and close to being harmful.

The criteria for eardrums are presented with respect to three levels of survival factors; see the dashed lines. The criteria apply to the aiming-kneeling person with the eardrums 
Fig. 4 Pressure histories for 200-g TNT charges and different positions, day 2
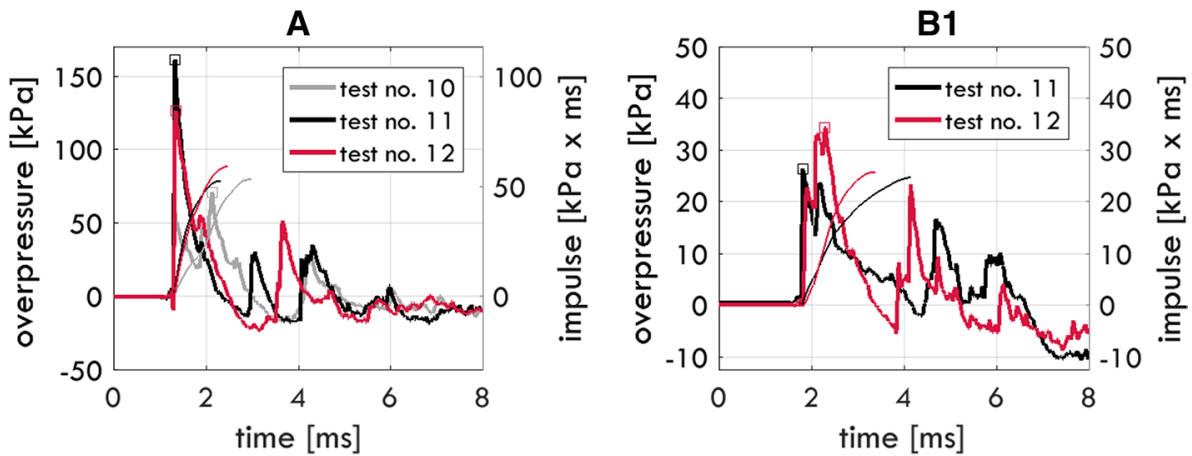

A
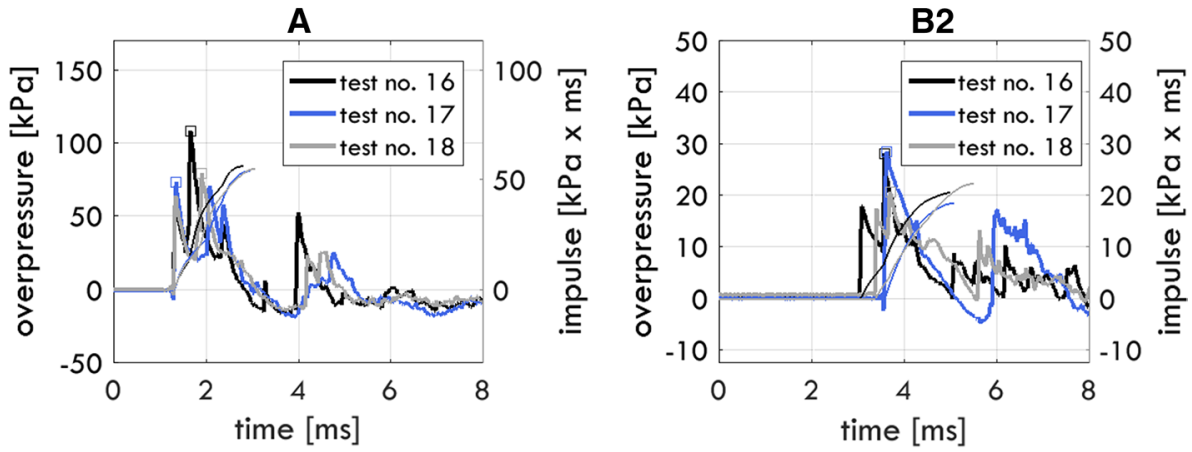

A

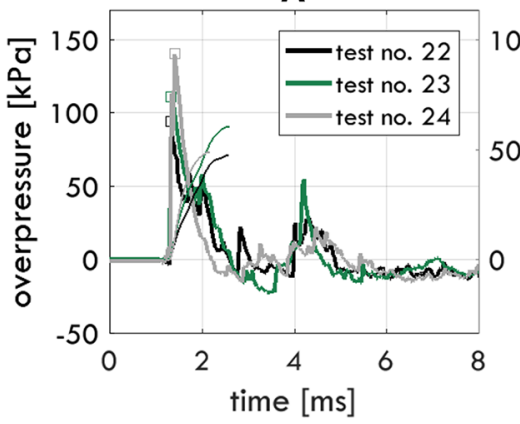

B3

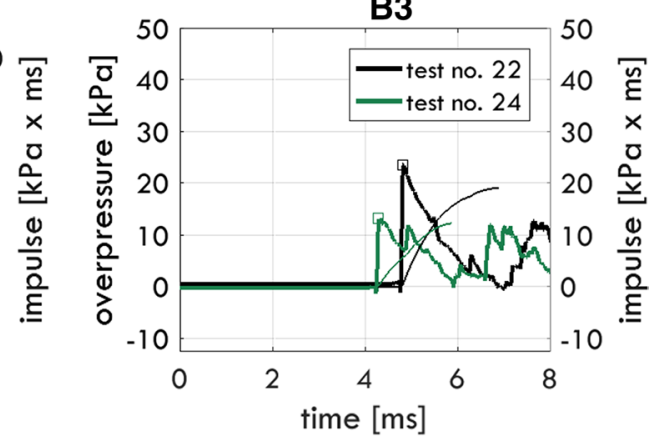

at $1.35 \mathrm{~m}$ from the ground. In Fig. 7, the red PI region is designated as a severe danger. The survival factor, based on [9], for this area equals 0.44 , which means that only 44 out of 100 people would avoid the eardrum damage. Based on the eardrum rupture safety criterion [23], a moderately dangerous space can be predicted between values of 35 and $90 \mathrm{kPa}$ (yellow area). This area includes the locations $\mathrm{B}_{2}$ and $\mathrm{B}_{3}$ for $400 \mathrm{~g}$ of TNT and $\mathrm{B}_{1}$ for $200 \mathrm{~g}$ of TNT. Finally, the green area in Fig. 7 is a safe space. The survival factor for the area equals 0.99 , which means that 99 out of 100 people would not be subjected to the eardrum damage [9]. It includes $B_{2}$ and $\mathrm{B}_{3}$ locations for $200 \mathrm{~g}$ of TNT; however, the 400 - $\mathrm{g}$ case is also acceptable when the distance from the corner is $1.5 \mathrm{~m}$ ( $\mathrm{B}_{3}$ location). The final thresholds are considered, respectively, to the average values presented in Fig. 7.

The data presented in the current paper may be used as the validation input for the numerical, analytical, or experimental studies. For instance, the data would be useful to validate the numerical model discussed in [24], in the same way as the data from [25] served for validating the numerical model presented in [26], where a large-scale scenario with square longitudinal obstacles was considered. Another example of such an approach is given in [27], where the test data from [28] were used to validate the masonry wall response. An example of an analytical study, in which the experimental data are used for validation, is [29] by Wang et al. The loading overpressure profiles presented here may also be used for comparison with the laboratory tests, similar to [4].

Numerical models of blast events can be validated by the experimental results presented here, even in the case of models considering a large and complex urban scenario. Such urban environments were considered in several numerical studies, such as [30-34]. Those complex tests including city geometry are not possible to conduct in reality due to economic and infrastructure access reasons. For a part of the numerical models, the results may be compared with the experimental outcomes presented here, and that makes the present data highly valuable for validating urban blast simulations. 
Fig. 5 Pressure histories for 400-g TNT charges and different positions, day 2
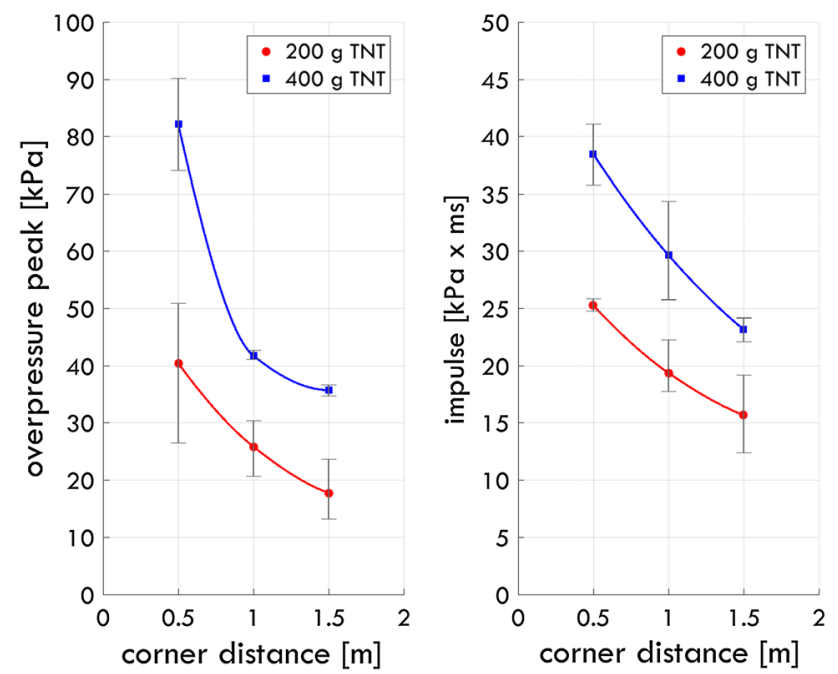

Fig. 6 The relation of averaged overpressure peaks (left) and positive impulses (right) to the distances behind the building corner
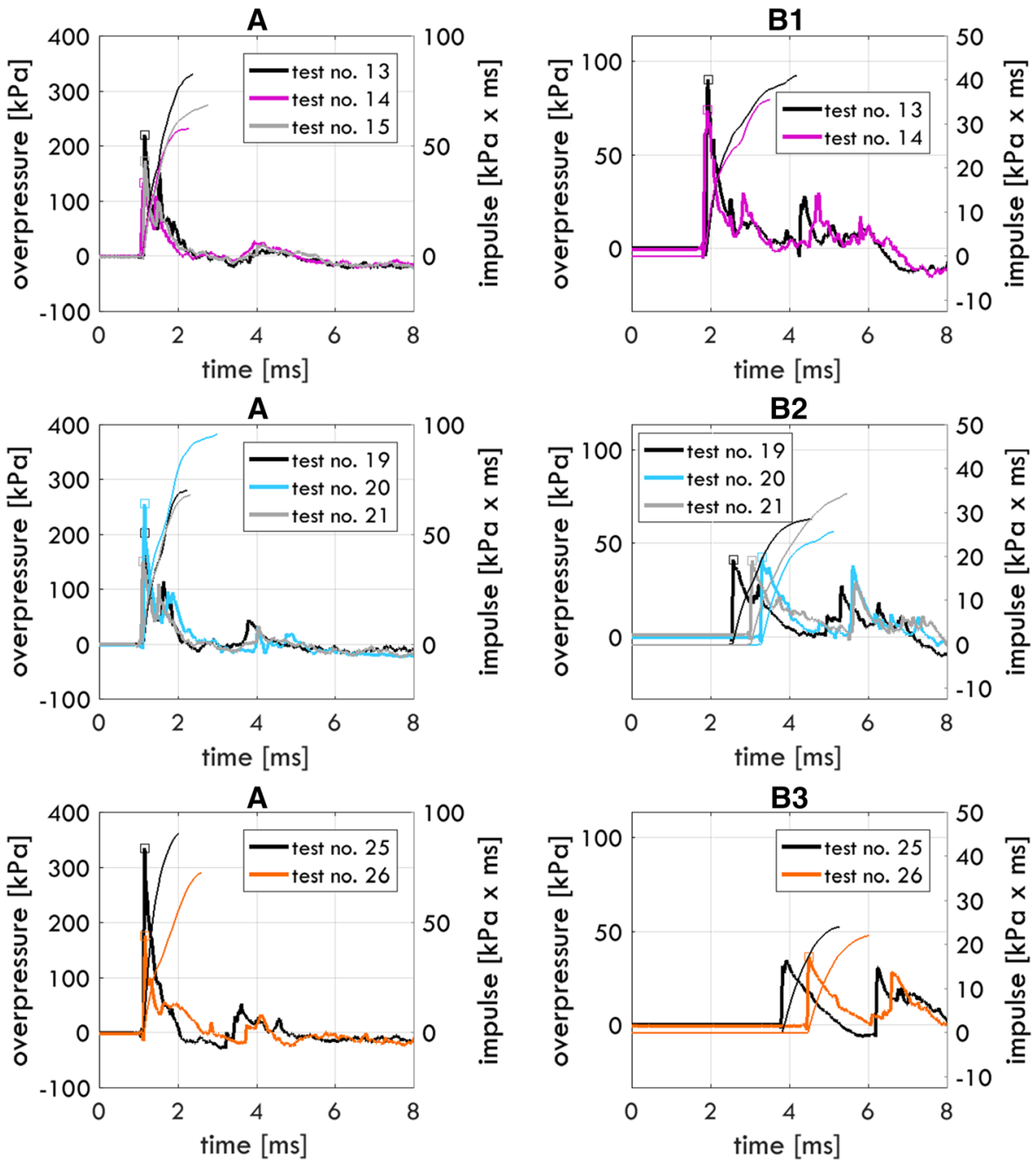

100

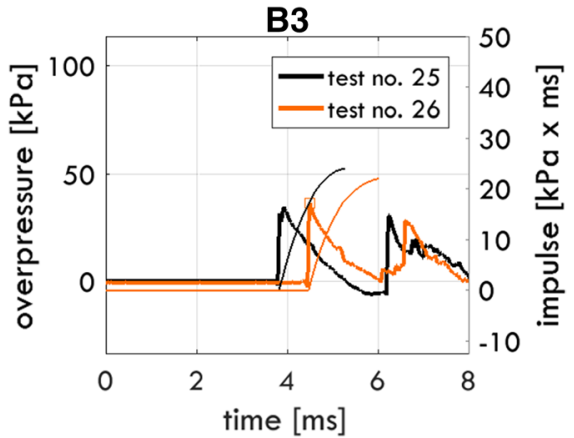

Table 3 Comparison of the results for the gauge at position A

\begin{tabular}{|c|c|c|c|c|c|}
\hline \multirow{2}{*}{$\begin{array}{l}\text { Charge } \\
\text { mass } \\
(\mathrm{g})\end{array}$} & \multirow{2}{*}{$\begin{array}{l}\text { Scaled } \\
\text { distance } \\
\left(\mathrm{m} \times \mathrm{kg}^{-1 / 3}\right)\end{array}$} & \multicolumn{2}{|c|}{$\begin{array}{l}\text { Empirical formulas } \\
{[9,17,18]}\end{array}$} & \multicolumn{2}{|c|}{ Present experiments } \\
\hline & & $\begin{array}{l}\text { Over- } \\
\text { pressure } \\
(\mathrm{kPa})\end{array}$ & $\begin{array}{l}\text { Positive } \\
\text { impulse } \\
(\mathrm{kPa} \times \mathrm{ms})\end{array}$ & $\begin{array}{l}\text { Over- } \\
\text { pressure } \\
(\mathrm{kPa})\end{array}$ & $\begin{array}{l}\text { Positive } \\
\text { impulse } \\
(\mathrm{kPa} \times \mathrm{ms})\end{array}$ \\
\hline 200 & 2.31 & 142 & 47 & 109 & 60 \\
\hline 400 & 1.83 & 237 & 74 & 206 & 76 \\
\hline
\end{tabular}

It should be noted that the incident pressure is measured in the experiment. However, the real pressures acting on an obstacle (e.g., a human body) are different and more related to the reflected pressure value. This value depending on the incident angle could be even twice larger than the incident pressure. 


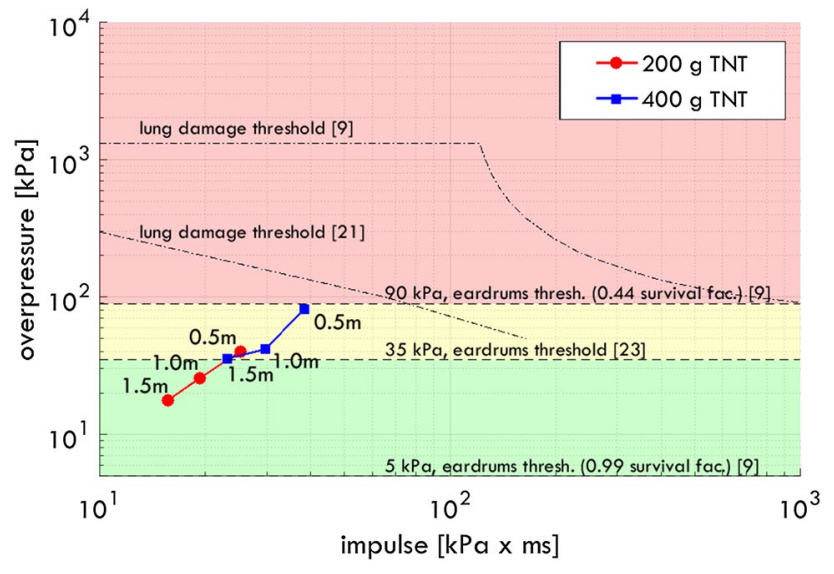

Fig. 7 Overpressure versus impulse plot with different damage/safety criteria

\section{Concluding summary}

The present paper reports the experimental study on blast wave propagation caused by TNT explosions behind the corner of a rigid structure. The loading scenarios reflect hypothetical but realistic situations in which such people as the members of special forces or civilians hide from an explosion. The primary objective was to find the loading conditions at various distances from the building corner for two scenarios (different masses of TNT charges). The final overpressure-impulse plot was derived from 27 actual explosive tests. The empirical formulas are in agreement with the presented experimental outcomes. The summary data of impulses and average overpressure peaks are presented. The data in the selected cases demonstrate low testto-test variability. Moreover, the relationships of the maximal overpressure to the distances behind the building corner were defined. The presented data can be further used for numerical validation and the verification of other studies, in which various charges and distances are considered.

Acknowledgements This work was supported by the National Centre for Research and Development Poland under the grant DOBBIO10/01/02/2019 in frame of Defense and Security Programme.

Open Access This article is licensed under a Creative Commons Attribution 4.0 International License, which permits use, sharing, adaptation, distribution and reproduction in any medium or format, as long as you give appropriate credit to the original author(s) and the source, provide a link to the Creative Commons licence, and indicate if changes were made. The images or other third party material in this article are included in the article's Creative Commons licence, unless indicated otherwise in a credit line to the material. If material is not included in the article's Creative Commons licence and your intended use is not permitted by statutory regulation or exceeds the permitted use, you will need to obtain permission directly from the copyright holder. To view a copy of this licence, visit http://creativecommons.org/licenses/by/4.0/.

\section{Appendix}

See Table 4.

Table 4 Full set-up of the experimental tests

\begin{tabular}{|c|c|c|c|c|}
\hline No. & $\begin{array}{l}\text { Charge } \\
\text { mass }(g)\end{array}$ & $\begin{array}{l}\text { Charge dimensions } \\
(\mathrm{mm} \times \mathrm{mm} \times \mathrm{mm})\end{array}$ & $\begin{array}{l}\text { Position of } \\
\text { gauge } 1\end{array}$ & $\begin{array}{l}\text { Position } \\
\text { of gauge } \\
2\end{array}$ \\
\hline 1 & 200 & $5 \times 2.5 \times 10$ & A & B1 \\
\hline 2 & 200 & $5 \times 2.5 \times 10$ & A & B1 \\
\hline 3 & 200 & $5 \times 2.5 \times 10$ & A & B1 \\
\hline 4 & 200 & $5 \times 2.5 \times 10$ & $\mathrm{~A}$ & B2 \\
\hline 5 & 200 & $5 \times 2.5 \times 10$ & A & B2 \\
\hline 6 & 200 & $5 \times 2.5 \times 10$ & A & B2 \\
\hline 7 & 200 & $5 \times 2.5 \times 10$ & A & B3 \\
\hline 8 & 200 & $5 \times 2.5 \times 10$ & A & B3 \\
\hline 9 & 200 & $5 \times 2.5 \times 10$ & A & B3 \\
\hline 10 & 200 & $5 \times 2.5 \times 10$ & A & - \\
\hline 11 & 200 & $5 \times 2.5 \times 10$ & A & B1 \\
\hline 12 & 200 & $5 \times 2.5 \times 10$ & A & B1 \\
\hline 13 & 400 & $5 \times 5 \times 10$ & A & B1 \\
\hline 14 & 400 & $5 \times 5 \times 10$ & A & B1 \\
\hline 15 & 400 & $5 \times 5 \times 10$ & A & - \\
\hline 16 & 200 & $5 \times 2.5 \times 10$ & A & B2 \\
\hline 17 & 200 & $5 \times 2.5 \times 10$ & A & B2 \\
\hline 18 & 200 & $5 \times 2.5 \times 10$ & A & B2 \\
\hline 19 & 400 & $5 \times 5 \times 10$ & A & B2 \\
\hline 20 & 400 & $5 \times 5 \times 10$ & A & B2 \\
\hline 21 & 400 & $5 \times 5 \times 10$ & A & B2 \\
\hline 22 & 200 & $5 \times 2.5 \times 10$ & A & B3 \\
\hline 23 & 200 & $5 \times 2.5 \times 10$ & A & - \\
\hline 24 & 200 & $5 \times 2.5 \times 10$ & A & B3 \\
\hline 25 & 400 & $5 \times 5 \times 10$ & A & B3 \\
\hline 26 & 400 & $5 \times 5 \times 10$ & A & B3 \\
\hline 27 & 400 & $5 \times 5 \times 10$ & - & - \\
\hline
\end{tabular}

Charge locations and the A, B1, B2, and B3 positions were fixed in all trials (Fig. 1)

\section{References}

1. Nurick, G.N., Mahoi, S., Langdon, G.S.: The response of plates subjected to loading arising from the detonation of different shapes of plastic explosive. Int. J. Impact Eng. 89, 102-113 (2016). https://doi.org/10.1016/j.ijimpeng.2015.11.012

2. Needham, C.E., Ritzel, D., Rule, G.T., Wiri, S., Young, L.: Blast testing issues and TBI: experimental models that lead to wrong conclusions. Front. Neurol. 6(72), 1-10 (2015). https://doi. org/10.3389/fneur.2015.00072

3. Pennetier, O., William-Louis, M., Langlet, A.: Numerical and reduced-scale experimental investigation of blast wave shape in underground transportation infrastructure. Process Saf. Environ. Prot. 94, 96-104 (2015). https://doi.org/10.1016/j. psep.2015.01.002 
4. Sochet, I., Eveillard, S., Vinçont, J.Y., Piserchia, P.F., Rocourt, X.: Influence of the geometry of protective barriers on the propagation of shock waves. Shock Waves 27, 209-219 (2016). https://doi. org/10.1007/s00193-016-0625-4

5. Hao, H., Hao, Y., Li, J., Chen, W.: Review of the current practices in blast-resistant analysis and design of concrete structures. Adv. Struct. Eng. 19, 1193-1223 (2016). https://doi.org/10.1177/13694 33216656430

6. Sugiyama, Y., Izumo, M., Ando, H., Matsuo, A.: Two-dimensional explosion experiments examining the interaction between a blast wave and a sand hill. Shock Waves 28, 627-630 (2018). https:// doi.org/10.1007/s00193-018-0813-5

7. Anderson, C.E., Behner, T., Weiss, C.E.: Mine blast loading experiments. Int. J. Impact Eng. 38, 697-706 (2011). https://doi. org/10.1016/j.ijimpeng.2011.04.005

8. Acosta, P.F.: Overview of UFC 3-340-02 structures to resist the effects of accidental explosions. Structures Congress, Las Vegas, NV (2011). https://doi.org/10.1061/41171(401)127

9. UFC. Unified Facilities Criteria: Structures to Resist the Effects of Accidental Explosions. Report No. UFC-3-340-02. US Department of Defence, Washington, DC (2008)

10. Codina, R., Ambrosini, D.: Full-scale testing of leakage of blast waves inside a partially vented room exposed to external air blast loading. Shock Waves 28, 227-241 (2017). https://doi. org/10.1007/s00193-017-0733-9

11. Chi, L.Y., Zhang, Z.-X., Aalberg, A., Yang, J., Li, C.C.: Measurement of shock pressure and shock-wave attenuation near a blast hole in rock. Int. J. Impact Eng. 125, 27-38 (2019). https://doi. org/10.1016/j.ijimpeng.2018.11.002

12. Zheng, C., Kong, X.-S., Wu, W.-G., Xu, S.-X., Guan, Z.-W.: Experimental and numerical studies on the dynamic response of steel plates subjected to confined blast loading. Int. J. Impact Eng. 113, 144-160 (2018). https://doi.org/10.1016/j.ijimp eng.2017.11.013

13. Linforth, S., Tran, P., Rupasinghe, M., Nguyen, N., Ngo, T., Saleh, M., Odish, R., Shanmugam, D.: Unsaturated soil blast: flying plate experiment and numerical investigations. Int. J. Impact Eng. 125, 212-228 (2019). https://doi.org/10.1016/j.ijimpeng.2018.08.002

14. Sielicki, P.W.: Masonry Failure Under Unusual Impulse Loading. Publishing House of Poznan University of Technology, Poznan (2013)

15. Sielicki, P.W., Gajewski, T.: Numerical assessment of the human body response to a ground-level explosion. Comput. Methods Biomech. Biomed. Eng. 22, 180-205 (2019). https://doi. org/10.1080/10255842.2018.1544628

16. Ouellet, S., Philippens, M.: Correction to: the multi-modal responses of a physical head model subjected to various blast exposure conditions. Shock Waves 28, 437 (2017). https://doi. org/10.1007/s00193-017-0771-3

17. Sielicki, P.W., Stachowski, M.: Implementation of sapper-blastmodule, a rapid prediction software for blast wave properties. Central Eur. J. Energ. Mater. 12(3), 473-486 (2015)

18. Kingery, C.N., Bulmash, G.: Airblast parameters from TNT spherical air burst and hemispherical surface burst. Report No. ARBRL-TR-02555. US Army BRL, Aberdeen Proving Ground (1984)

19. Gurdjian, E.S., Roberts, V.L., Thomas, L.M.: Tolerance curves of acceleration and intracranial pressure and protective index in experimental head injury. J. Trauma 6, 600-604 (1966). https:// doi.org/10.1097/00005373-196609000-00005

20. Burkacki, M., Suchoń, S., Joszko, K., Gzik-Zroska, B., Wojtkowski, M., Wolański, W., Gzik, M.: Impact of soldiers' inventories on the risk of injury during IED blast under a light armored vehicle. Eng. Trans. 65, 579-585 (2017)
21. Ono, K., Kikuchi, A., Nakamura, M., Kobayashi, H., Nakamura, N.: Human head tolerance to sagittal impact reliable estimation deduced from experimental head injury using subhuman primates and human cadaver skulls. SAE Technical Paper 801303 (1980). https://doi.org/10.4271/801303

22. Walpole, S.C., Prieto-Merino, D., Edwards, P., Cleland, J., Stevens, G., Roberts, I.: The weight of nations: an estimation of adult human biomass. BMC Public Health 12(439), 1-6 (2012). https:// doi.org/10.1186/1471-2458-12-439

23. Beveridge, A.: Forensic Investigation of Explosions. CRC Press, Boca Raton (1998). https://doi.org/10.1201/b11938

24. Rejmont, J., Stoller, J.: Design of building protection in peacekeeping operations of the armed forces of the Czech Republic based on simulations of the effects of blast wave. International Conference on Military Technologies, Brno, Czech Republic (2015). https://doi.org/10.1109/miltechs.2015.7153674

25. Catlin, C., Ivings, M., Myatt, S.: Explosion Hazard Assessment: A Study of the Feasibility and Benefits of Extending Current HSE Methodology to Take Account of Blast Sheltering. Health and Safety Laboratory, Buxton (2001)

26. Benselama, A.M., William-Louis, M.J.-P., Monnoyer, F.: Prediction of blast wave effects on a developed site. Int. J. Impact Eng. 37, 385-396 (2010). https://doi.org/10.1016/j.ijimp eng.2009.08.003

27. Wei, X., Stewart, M.G.: Model validation and parametric study on the blast response of unreinforced brick masonry walls. Int. J. Impact Eng. 37, 1150-1159 (2010). https://doi.org/10.1016/j.ijimp eng.2010.04.003

28. Varma, R.K., Tomar, C.P.S., Parkash, S., Sethi, V.S.: Damage to brick masonry panel walls under high explosive detonations. American Society of Mechanical Engineers, Pressure Vessels and Piping Division (Publication) PVP, vol. 351, pp. 207-209 (1997)

29. Wang, Y., Yang, Y.L., Wang, S., Huang, Z.L., Yu, T.X.: Dynamic behavior of circular ring impinging on ideal elastic wall: analytical model and experimental validation. Int. J. Impact Eng. 122, 148-160 (2018). https://doi.org/10.1016/j.ijimpeng.2018.07.009

30. Cullis, I.G., Nikiforakis, N., Frankl, P., Blakely, P., Bennett, P., Greenwood, P.: Simulating geometrically complex blast scenarios. Def. Technol. 12, 134-146 (2016). https://doi.org/10.1016/j. dt.2016.01.005

31. Hank, S., Saurel, R., Le Métayer, O., Lapébie, E.: Modeling blast waves, gas and particles dispersion in urban and hilly ground areas. J. Hazard. Mater. 280, 436-449 (2014). https://doi. org/10.1016/j.jhazmat.2014.08.011

32. Chen, W., Su, H., Yong, Y., Hu, Z.: Decision support system for urban major hazard installations management based on 3DGIS. Phys. Chem. Earth Parts A/B/C 110, 203-210 (2018). https://doi. org/10.1016/j.pce.2018.08.008

33. Wang, X., Remotigue, M., Arnoldus, Q., Janus, M., Luke, E., Thompson, D., Weed, R., Bessette, G.: High-fidelity simulations of blast loadings in urban environments using an overset meshing strategy. Shock Waves 27, 409-422 (2016). https://doi. org/10.1007/s00193-016-0680-x

34. Reitsma, H.J.: The explosion of a ship, loaded with black powder, in Leiden in 1807. Int. J. Impact Eng. 25, 507-514 (2001). https ://doi.org/10.1016/S0734-743X(00)00067-1

Publisher's Note Springer Nature remains neutral with regard to jurisdictional claims in published maps and institutional affiliations. 